\title{
Cd Content with an Always High Vertical Diluted Amount
}

\author{
Dongfang Yang ${ }^{1,2, \text { a }}$,Xinmin Huang ${ }^{1}$, TaoJiang ${ }^{1}$,LinzhenWei ${ }^{1}$,Shengjun Zhang ${ }^{1}$ \\ ${ }^{1}$ School of International Economics, Shaanxi Institute of International Trade \& commerce, Xi'an 712046, China; \\ ${ }^{2}$ North China Sea Environmental Monitoring Center, SOA, Qingdao 266033, China;
}

\begin{abstract}
Based on the investigation data about Cd in Jiaozhou Bay in August 1992 and the horizontal change model of matter content and the vertical change model of matter content proposed by the authors, the horizontal loss amount, vertical diluted amount and vertical sediment amount of Cd content in the surface and bottom layers from the southeast waters of the bay to the west waters of the bay mouth were calculated, and the model block diagram of the horizontal and vertical changes of $\mathrm{Cd}$ content was determined. The results show that in August, the absolutely loss amount of $\mathrm{Cd}$ content in the surface layer was $0.09 \mu \mathrm{g} / \mathrm{L}$, and the absolutely increase amount of $\mathrm{Cd}$ content in the bottom layer was $0.10 \mu \mathrm{g} / \mathrm{L}$. The relatively loss amount of $\mathrm{Cd}$ content in the surface layer was $12.00 \%$, and the relatively increase amount of $\mathrm{Cd}$ content in the bottom layer was $41.66 \%$. Cd content in the surface and bottom layershadabsolutely vertical diluted amount of $0.42-0.61 \mu \mathrm{g} / \mathrm{L}$, and its relatively vertical diluted amount was $63.63-81.33 \%$. In August, in the horizontal migration of $\mathrm{Cd}$ content in the surface and bottom layers, the main sea current carried high $\mathrm{Cd}$ content in the surface waters. And after passing through the nearshore waters of the bay, one tenth of the Cd content in the surface layer settled to the seabed. In the horizontal migration process of $\mathrm{Cd}$ content in the surface layer, the loss amount of $\mathrm{Cd}$ content in the surface layer reached $12.00 \%$ in the nearshore waters around Jiaozhou Bay, thus the increase amount of $\mathrm{Cd}$ content in the bottom layer reached $41.66 \%$. It reveals that the high $\mathrm{Cd}$ content in the surface layer could rapidly and continuously sink to the seabed, and the Cd content in the seabed waters in Jiaozhou Bay increased by $41.66 \%$. In August, in the process of vertical migration, the $\mathrm{Cd}$ content transported by main sea current was relatively high, and the vertical diluted amount of $\mathrm{Cd}$ content in the surface and bottom layers was high $63.63-81.33 \%$ from the southeast waters of the bay to the waters in the west of the bay mouth.
\end{abstract}

\section{Introduction}

The main sea current enters Jiaozhou Bay with high content of cadmium $(\mathrm{Cd})$ and goes from outside the bay through the bay mouth to inside the bay, which causes the Cd content in the seawater surface in Jiaozhou Bay to increase. In the horizontal migration process, $\mathrm{Cd}$ content migrates from one water surface to another. While in the process of vertical migration, it passes through the water body from the surface and sinks to the seabed [1-6]. Therefore, using the horizontal and vertical matter content change models proposed by the authors and the investigation data about Cd content in Jiaozhou Bay in August, 1992, the horizontal migration process and vertical sediment process of $\mathrm{Cd}$ content in Jiaozhou Bay waters are demonstrated, and the pollution process and pollution degree of polluted water bodies caused by $\mathrm{Cd}$ content transported by main sea current are explained, which provides scientific basis for the study of vertical sediment and horizontal migration of $\mathrm{Cd}$ content in the surface and bottom waters.
Located in the south of Shandong Peninsula, $120^{\circ} 04^{\prime}$ $120^{\circ} 23^{\prime} \mathrm{E}$ and $35^{\circ} 58^{\prime}-36^{\circ} 18^{\prime} \mathrm{N}$,JiaozhouBay is bounded by the connecting line between Tuan Island and Xuejia Island and communicates with the Yellow Sea, with an area of about $446 \mathrm{~km}^{2}$ and an average water depth of about $7 \mathrm{~m}$. It is a typical semi-enclosed bay. There are more than a dozen rivers flowing into the sea in Jiaozhou Bay, among which Dagu River and Yanghe River, and Haibo River, Licun River and Loushan River in Qingdao urban area are with large runoff and sediment concentration $[7,8]$.

\subsection{Materials and Methods}

The investigation data about $\mathrm{Cd}$ in Jiaozhou Bay in August 1992 used in this study were provided by North China Sea Environmental Monitoring Center, SOA. In August, water samples were taken at two sites in Jiaozhou Bay: site 60 and site 53 (Figure 1) according to water depth. By the national standard method included in the National Specification for Marine Monitoring (1991) [9], the Cd in Jiaozhou Bay was investigated.

\section{Waters, Materials and Methods}

\subsection{Natural Environment of Jiaozhou Bay}

adfyang_dfyang@126.com 


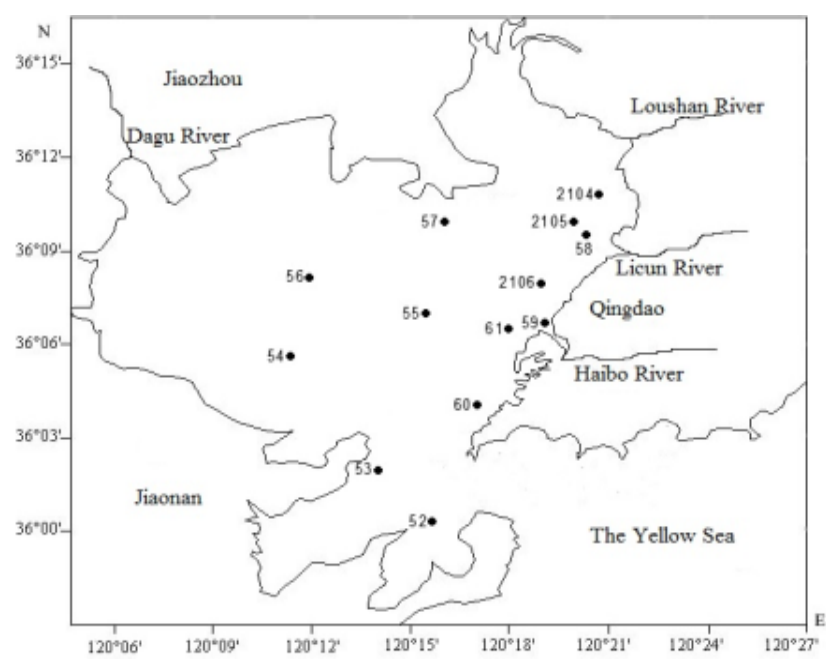

Figure.1. Investigation sites in Jiaozhou Bay

\section{Results}

\subsection{Waters from Southeast Bay to West Bay Mouth}

The main sea current entered Jiaozhou Bay with high content of $\mathrm{Cd}$ through the bay mouth. In addition, the current circled the nearshore waters in the bay, then reached the western waters of the bay mouth and left Jiaozhou Bay (Figure 2).

In August in the southeast waters of Jiaozhou Bay, the site is 60 . In the western waters of Jiaozhou Bay, the site is 53. In the surface waters, the main sea current entered the bay waters through the southern waters of bay mouth, and reached site 60 , with $\mathrm{Cd}$ content of $0.75 \mu \mathrm{g} / \mathrm{L}$. Then the main sea current circled the nearshore waters of the bay, and reached site 53 , with $\mathrm{Cd}$ content of $0.66 \mu \mathrm{g} / \mathrm{L}$. In the bottom waters, the main sea current entered the bay waters through the southern waters of bay mouth, and reached site 60 , with a Cd content of $0.14 \mu \mathrm{g} / \mathrm{L}$. Then the main sea current circled the nearshore waters of the bay, and reached site 53 with a Cd content of $0.24 \mu \mathrm{g} / \mathrm{L}$. Accordingly, with the movement of the bay current, the $\mathrm{Cd}$ content in the surface waters was constantly decreasing. However, in the bottom waters in the west of the bay mouth, the sediment of $\mathrm{Cd}$ content increased.

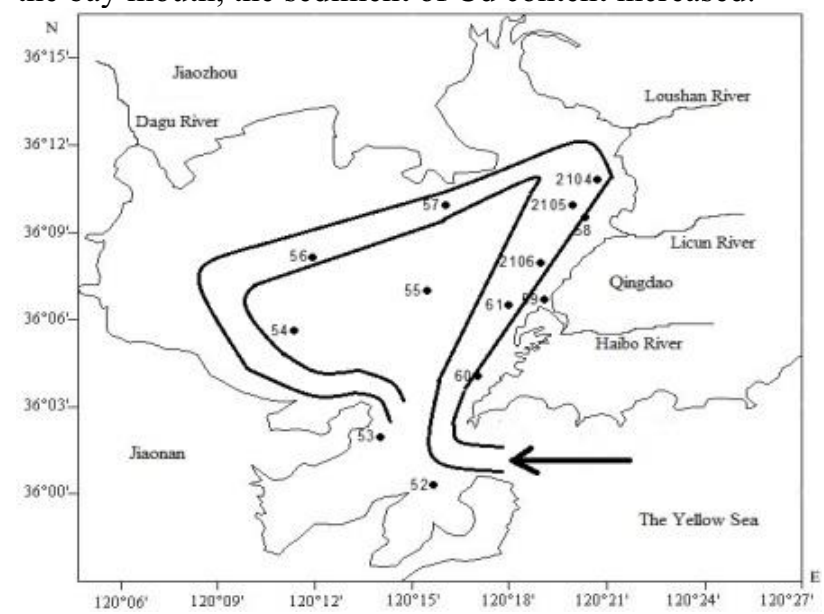

Figure.2. The flow path of the main sea current with high matter content in Jiaozhou Bay $(\mu \mathrm{g} / \mathrm{L})$

\subsection{The Definitions of Changes in the Content of Horizontal Matter Content}

In Jiaozhou Bay, the current carried matter content. And with the movement of the current, the matter content decreased continuously [10-13]. According to the definitions and formulae put forward by the authors, the horizontal loss amount, vertical diluted amount and vertical sediment amount of matter content are calculated. The horizontal loss amount of matter content can be divided into absolutely horizontal loss amount and relatively horizontal loss amount. The vertical diluted and sediment amounts of matter content can be divided into absolutely vertical diluted and sediment amounts and relatively vertical diluted and sediment amounts.

\subsection{Formulae for Changes of Horizontal Matter Content}

In the surface waters from southeast bay to west bay mouth, it is assumed that the matter (M) content is A in southeast bay and B in west bay mouth.

The absolutely horizontal loss amount of matter content is $\mathrm{D}>0$ and the relatively horizontal loss amount is $\mathrm{E}$ from southeast bay waters to west bay waters. When $\mathrm{D}<0$, it means that the absolutely horizontal loss amount of matter content is $-\mathrm{D}>0$; when $\mathrm{D}<0$, it means that the absolutely horizontal increase amount of matter content from southeast bay waters to west bay waters is $-\mathrm{D}>0$.

$$
\mathrm{D}=\mathrm{A}-\mathrm{B}, \quad \mathrm{E}=|\mathrm{A}-\mathrm{B}| / \max (\mathrm{A}, \mathrm{B})
$$

In the bottom waters from southeast bay to west bay mouth, it is assumed that the matter content is a in southeast bay and $b$ in west bay mouth.

The absolutely horizontal loss amount of matter content is $d>0$ and the relatively horizontal loss amount is e from southeast bay waters to west bay waters. When $\mathrm{d}<0$, it means that the absolutely horizontal loss amount of matter content is $-d>0$; when $d<0$, it means that the absolutely horizontal increase amount of matter content from southeast bay waters to west bay waters is $-\mathrm{d}>0$.

$$
\mathrm{d}=\mathrm{a}-\mathrm{b}, \quad \mathrm{e}=|\mathrm{a}-\mathrm{b}| / \max (\mathrm{a}, \mathrm{b})
$$

\subsection{Formula for Changes of Vertical Matter Content}

In the waters from southeast bay to west bay mouth, it is assumed that the matter content in the surface waters of southeast bay is A, and that in the bottom waters is a. It is assumed that the water site is $\mathrm{n}$, and the absolutely vertical diluted amount of matter content is $\mathrm{V}_{\mathrm{na}}>0$ and the relatively vertical diluted amount of matter content is $\mathrm{V}_{\mathrm{nr}}$. When $\mathrm{V}_{\text {na }}<0$, the absolutely vertical sediment amount of matter content is $-\mathrm{V}_{\mathrm{na}}>0$, and the relatively vertical sediment amount of matter content is $\mathrm{V}_{\mathrm{nr}}$.

$$
\mathrm{Vna}=\mathrm{A}-\mathrm{a}, \quad \mathrm{Vnr}=|\mathrm{A}-\mathrm{a}| / \max (\mathrm{A}, \mathrm{a})
$$

\subsection{Horizontal Loss Amount of Cd Content in the surface Layer and Bottom Layer}

It is assumed that from site 60 to site 53 is simply from A to $\mathrm{B}$. matter content is mainly $\mathrm{Cd}$ content, and the horizontal loss amount of $\mathrm{Cd}$ content in the surface and 
bottom layer is revealed through the horizontal change of Cd content.

In August, in the surface waters from southeast bay to west bay, passing through the nearshore waters of the bay, the $\mathrm{Cd}$ content in the surface layer changed greatly [10]. The horizontal loss amount of Cd content in the surface layer was calculated by formula (1) (Table 1).

Table1. Horizontal loss amount of $\mathrm{Cd}$ content in the surface layer

\begin{tabular}{|c|c|c|c|}
\hline from A to B & D & E & E \\
\hline August & 0.09 & 0.1200 & $12.00 \%$ \\
\hline
\end{tabular}

In August, in the bottom waters of from the southeast of bay to the west of bay mouth, passing through the nearshore waters of bay, the $\mathrm{Cd}$ content in the bottom layer varied much [10], and the horizontal increase amount of Cd content in the bottom layer was calculated by formula (2) (Table 2).

Table2. Horizontal increase amount of Cd content in the bottom layer

\begin{tabular}{|c|c|c|c|}
\hline from A to B & d & e & e \\
\hline August & -0.10 & 0.4166 & $41.66 \%$ \\
\hline
\end{tabular}

\subsection{Vertical Diluted and Vertical Sediment Amounts}

Cd content is the main part of matter content. The vertical diluted and vertical sediment amounts of $\mathrm{Cd}$ content in the surface and bottom layers are revealed through the vertical changes of Cd content.

In August, in Jiaozhou Bay, from the southeast of the bay to the west of the bay mouth, the Cd content in the surface and bottom of the waters changed a lot [11-13]. Through formula (3), the vertical diluted and sediment amounts of $\mathrm{Cd}$ content in the surface and bottom layers are calculated (Table 3).

Table3. Vertical diluted and sediment amounts of $\mathrm{Cd}$ content in the

\begin{tabular}{|c|c|c|c|c|}
\hline \multicolumn{5}{|c|}{ surface and bottom layers } \\
\hline \multirow{3}{*}{ Time } & Waters & $\mathrm{V}_{\mathrm{na}}$ & $\mathrm{V}_{\mathrm{nr}}$ & $\mathrm{V}_{\mathrm{nr}}$ \\
\hline \multirow{2}{*}{ August } & $\begin{array}{c}\text { Southeastern } \\
\text { waters of bay }\end{array}$ & 0.61 & 0.8133 & $81.33 \%$ \\
\cline { 2 - 5 } & $\begin{array}{c}\text { Southwestern } \\
\text { waters of bay }\end{array}$ & 0.42 & 0.6363 & $63.63 \%$ \\
\hline
\end{tabular}

\section{Discussion}

\subsection{Changes in Matter Content of Current Track in the Bay}

Jiaozhou Bay is a shallow bay, which is generally dustpan-shaped, inclining straight and then inclining eastward in the bay mouth area, and its water is shallow in northwest and deep in southeast (Figure 3). The main sea current entered Jiaozhou Bay with high content of $\mathrm{Cd}$ from outside the bay through the bay mouth. The current flowed along the nearshore waters in the northeast of the bay toward the bay head waters in the northeast of the bay, reaching the estuary waters of Loushan River. Then it turned to the west and passed through the coastal waters in the northern part of the bay. After that, it went to the westernmost waters in the northwest of the Bay, reaching the estuary waters of Dagu River. Finally, it turned to the south along the nearshore waters in the west of the Bay, and reached the bay mouth waters (Figure 2).
So, the main sea current entered Jiaozhou Bay with high content of $\mathrm{Cd}$ and surrounded a circle of nearshore waters in the bay.

In the migration process the matter content changed. In Jiaozhou Bay waters in August, the Cd content was $1.11 \mu \mathrm{g} / \mathrm{L}$ from the transportation of the main sea current. The main sea current entered the bay waters, passing through site 60 and site 53. According to the principle of matter vertical water body effect, matter horizontal water body effect and water body effect proposed by the authors [11-13], the horizontal changes of matter content reveal the loss effect of horizontal water body, while the changes of matter content in the surface and bottom layers reveal the sediment effect and dilluted effect of vertical water body. Thus, the horizontal and vertical migration processes of $\mathrm{Cd}$ content in the waters from the southeast of bay to the west of bay mouth are quantitatively studied through the horizontal and vertical matter content change model designed by the authors.

\subsection{Horizontal and Vertical Changes of $\mathrm{Cd}$ Content}

On the spatial scale, in the surface water in the southeast of Jiaozhou Bay in August, the Cd content $1.11 \mu \mathrm{g} / \mathrm{L}$ was transported by the main sea current. In the surface waters the main sea current entered the bay waters through the southern waters of bay mouth, arriving at the southeast waters of Jiaozhou Bay. The $\mathrm{Cd}$ content in the surface waters was $0.75 \mu \mathrm{g} / \mathrm{L}$, which indicates that the $\mathrm{Cd}$ content in the surface waters was greatly reduced. When the current encircled the nearshore waters of the bay from the southeast of the bay to the west of the bay mouth, the $\mathrm{Cd}$ content in the surface layer was $0.66 \mu \mathrm{g} / \mathrm{L}$. It shows that in Jiaozhou Bay, under the action of tides and currents in the bay, the $\mathrm{Cd}$ content in the surface layer was decreasing along the gradient. However, the decline of $\mathrm{Cd}$ content in the surface layer was relatively small because the absolutely horizontal loss amount of $\mathrm{Cd}$ content in the surface layer was $0.09 \mu \mathrm{g} / \mathrm{L}$. The absolutely increase amount of $\mathrm{Cd}$ content in the bottom layer was $0.10 \mu \mathrm{g} / \mathrm{L}$ from the southeast of the bay to the west of the bay mouth, which reveals the high $\mathrm{Cd}$ content transported by the main sea current to Jiaozhou Bay. When the current left the bay, a part of $\mathrm{Cd}$ content remained at the bottom of Jiaozhou Bay.

When the main sea current entered the bay waters, the vertical diluted amount of $\mathrm{Cd}$ content in the surface and bottom layers reached a high value of $81.33 \%$ in the southeast waters of the bay, which shows that the $\mathrm{Cd}$ content in the surface layer underwent a large amount of sediment when the main sea current just entered the bay. When the main sea current left the bay waters, the vertical diluted amount of Cd content in the surface and bottom layers reached a high value of $63.63 \%$ in the western waters of the bay mouth, which indicates that when the main sea current just left the bay, the $\mathrm{Cd}$ content in the surface layer also underwent a large amount of sediment (Figure 3). 


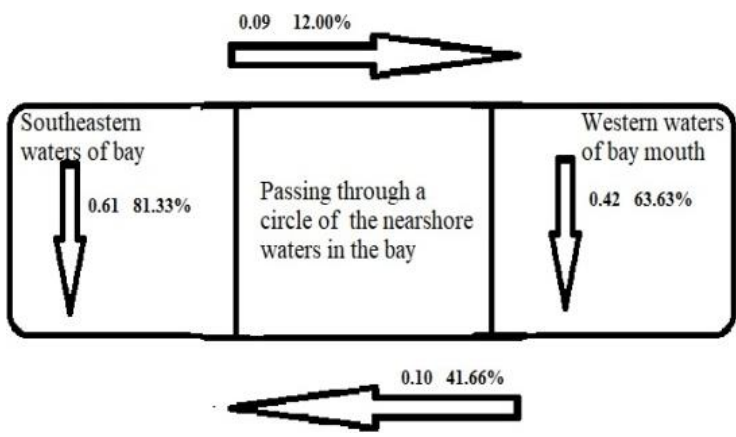

Figure.3. Model block diagram of horizontal and vertical changes of Cd content in August

Therefore, in August, the absolutely loss amount of $\mathrm{Cd}$ content in the surface layer was $0.09 \mu \mathrm{g} / \mathrm{L}$, and the absolutely increase amount of $\mathrm{Cd}$ content in the bottom layer was $0.10 \mu \mathrm{g} / \mathrm{L}$. The relatively loss amount of $\mathrm{Cd}$ content in the surface layer was $12.00 \%$, and the relatively increase amount of $\mathrm{Cd}$ content in the bottom layer was $41.66 \%$. Cd content in the surface and bottom layers had absolutely vertical diluted amount of $0.42-0.61 \mu \mathrm{g} / \mathrm{L}$, and its relatively vertical diluted amount was $63.63-81.33 \%$.

\subsection{Horizontal Loss Amount}

In August, the horizontal loss amount of $\mathrm{Cd}$ content in the surface layer reached a relatively low level of $12.00 \%$ when $\mathrm{Cd}$ content passed through a circle in the bay from the coastal waters in the southeast bay to the waters in the west of the bay mouth (Table 1). It indicates that only one tenth of the $\mathrm{Cd}$ content in the surface layer sank to the seabed. As a result, in the horizontal migration process, $12.00 \%$ of $\mathrm{Cd}$ content in the surface layer was lost and settled to the bottom of Jiaozhou Bay.

Meanwhile, the horizontal increaseamountof $\mathrm{Cd}$ content in the bottom layer reached $41.66 \%$ (Table 2) when $\mathrm{Cd}$ content passed through a circle in the bayfrom the coastal waters in the southeast bay to the waters in the west of the bay mouth. It indicates that a large amount of $\mathrm{Cd}$ content in the bottom layer sank to the seabed. With the increase of journey, the $\mathrm{Cd}$ content in the bottom layer also increased. So, $41.66 \%$ of the $\mathrm{Cd}$ content in the bottom layer increased in its own horizontal migration, remaining at the bottom of Jiaozhou Bay.

Therefore, in August in the surface water, the main sea current carried a high Cd content. And after passing through the nearshore waters in the bay, one tenth of the $\mathrm{Cd}$ content in the surface layer settled to the seabed. In the horizontal migration process, the loss amount of $\mathrm{Cd}$ content in the surface layer reached $12.00 \%$ in the nearshore waters around Jiaozhou Bay, thus the increase amount of $\mathrm{Cd}$ content in the bottom layer reached $41.66 \%$. It reveals that the high $\mathrm{Cd}$ content in the surface layer could rapidly and continuously sink to the seabed, and the Cd content in the seabed water in Jiaozhou Bay increased by $41.66 \%$.

\subsection{Vertical Loss Amount}

In Jiaozhou Bay in August, the Cd content transported by main sea current was $1.11 \mu \mathrm{g} / \mathrm{L}$. The main sea current first came to the surface water in the southeast bay where the vertical diluted amount of $\mathrm{Cd}$ content in the surface and bottom reached a high value of $81.33 \%$. Then itmoved from the waters in the southeast of the bay to the waters in the west of the bay mouth through the nearshore waters in a circle of the bay. In the western waters of bay mouth, the vertical diluted amount of $\mathrm{Cd}$ content in the surface and bottom reached a high value of $63.63 \%$.

It reveals that the high $\mathrm{Cd}$ content transported by the main sea current reached the southeast waters of the bay first. And the high $\mathrm{Cd}$ content in the surface layer could rapidly and continuously settle to the seabed where a high sediment and diluted amounts of $81.33 \%$ were obtained. Then, the main sea current passed through a circle of the nearshore waters in the bay and reached the waters in the west of the bay mouth. At this time, a relatively high sediment and diluted amounts of $63.63 \%$ were obtained at the seabed. Afterwards, the vertical diluted amount of $\mathrm{Cd}$ content in the surface and bottom layers reached a high value of $63.63-81.33 \%$ in the nearshore waters around Jiaozhou Bay. Accordingly, the high $\mathrm{Cd}$ content in the surface layer would rapidly sink to the bottom of Jiaozhou Bay from the nearshore waters around the bay to the waters in the west of the bay mouth.

Therefore, in August, in the process of vertical migration, the $\mathrm{Cd}$ content transported by main sea current was relatively high, and the vertical diluted amount of $\mathrm{Cd}$ content in the surface and bottom layers was also high $63.63-81.33 \%$ from the southeast waters of the bay to the waters in the west of the bay mouth.

\section{Conclusion}

On the basis of the horizontal and vertical matter content change models proposed by the authors, the horizontal loss amount, vertical diluted amount and vertical sediment amount of $\mathrm{Cd}$ content in the surface and bottom layers were calculated, and the model diagrams of horizontal and vertical changes of $\mathrm{Cd}$ content were determined.

In August, the absolutely loss amount of $\mathrm{Cd}$ content in the surface layer was $0.09 \mu \mathrm{g} / \mathrm{L}$ and the absolutely increase amount of $\mathrm{Cd}$ content in the bottom layer was $0.10 \mu \mathrm{g} / \mathrm{L}$. The relatively loss amount of $\mathrm{Cd}$ content in the surface layer was $12.00 \%$, and the relatively increase amount of $\mathrm{Cd}$ content in the bottom layer was $41.66 \%$. The $\mathrm{Cd}$ content in the surface and bottom layers had absolutely vertical diluted amount of $0.42-0.61 \mu \mathrm{g} / \mathrm{L}$, and its relatively vertical diluted amount was $63.63-81.33 \%$.

Only one tenth of the Cd content in the surface layer sank to the seabed from the coastal waters in the southeast of the bay to the waters in the west of the bay mouth through a circle in the bay. As a result, in the horizontal migration process of $\mathrm{Cd}$ content in the surface layer, $12.00 \%$ of $\mathrm{Cd}$ content in the surface layer was lost and settled to the bottom of Jiaozhou Bay.

A large amount of $\mathrm{Cd}$ content in the bottom layer sank to the seabed from the waters in the southeast of the bay to the waters in the west of the bay mouth through a circle of coastal waters of the bay. The Cd content in the bottom layer also increased with the increase of distance. So, $41.66 \%$ of the $\mathrm{Cd}$ content in the bottom layer 
increased in the horizontal migration and remained at the bottom of Jiaozhou Bay.

The high $\mathrm{Cd}$ content transported by the main sea current reached the southeast waters of the bay first, and the high Cd content in the surface layer could rapidly and continuously settle to the seabed where a high sediment and diluted amounts of $81.33 \%$ was obtained. Then, the main sea current passed through a circle of the nearshore waters in the bay and reached the waters in the west of the bay mouth. At this time, a relatively high sediment and diluted amounts of $63.63 \%$ were obtained at the seabed. As a result, the vertical diluted amountof $\mathrm{Cd}$ content in the surface and bottom layers reached a high value of $63.63-81.33 \%$ in the nearshore water around Jiaozhou Bay.

\section{References}

1. Dongfang Yang, Fengyou Wang, Sixi Zhu, ChunhuaSu and Xiuqin Yang. The influence of river on Cd contents in Jiaozhou Bay [J]. World Scientific Research Journal, 2017, 3(1): 1-5.

2. Dongfang Yang, Haixia Li, Xiaolong Zhang, Jiangmin Li, Nan Nan. The back and forth transformation between homogeneity and heterogeneity of $\mathrm{Cd}$ in marine bay [J]. Advances in Engineering Research, 2017, 138: 847-850.

3. Dongfang Yang, Zhenqing Miao, Haixia Li, Longlei Zhang, Qi Wang. Different stages of Cd's transporting process in waters in Jiaozhou Bay [J]. Earth and Environment Science, 2017, 81(012094): 1-6.

4. Dongfang Yang, Qiang Wang, Zhikang Wang, Sixi Zhu, ChunhuaSu. The changes of $\mathrm{Cd}$ sources in Jiaozhou Bay 1979-1983 [J]. Earth and Environment Science, 2017, 81(012095): 1-4.

5. Dongfang Yang, Linzhen Wei, Ming Feng, Mei Chen, Zhenqing Miao. Transport process and block diagram of $\mathrm{Cd}$ in Jiaozhou Bay [J]. Earth and Environment Science, 2017, 81(012096): 1-5.

6. Dongfang Yang, Qiang Wang, Ming Wang, Zhikang Wang, Sixi Zhu. Annual changes and seasonal variations of $\mathrm{Cd}$ in Jiaozhou Bay 1979-1983 [J]. Advances in Engineering Research, 2017, 141: 1587-1590.

7. YANG D F, CHEN Y, GAO Z H, et al. Silicon Limitation on primary production and its destiny in Jiaozhou Bay, ChinaIV transect offshore the coast with estuaries [J]. Chin. J. Oceanol. Limnol. 2005, 23(1): 72-90.

8. Dongfang Yang, Fan Wang, Zhenhui Gao, et al. Ecological Phenomena of Phytoplankton in Jiaozhou Bay [J]. Marine Science, 2004, 28 (6): 71-74.

9. State Oceanic Administration. The Specification for Marine Monitoring [Z]. Beijing: China Ocean Press, 1991.

10. Dongfang Yang, Zhenqing Miao, Huanzhi Xu, Yu Chen, Jingya Sun. Jiaozhou Bay water exchange time [J]. Marine Environmental Science, 2013, 32 (3): 373-380.

11. Dongfang Yang, Fengyou Wang, Huozhong He, Sixi Zhu and Yunjie Wu. Vertical water body effect of benzene hexachloride[J]. Proceedings of the 2015 international symposium on computers and informatics. 2015, 2655-2660.

12. Dongfang Yang, Fengyou Wang, Xiaoli Zhao, Yunjie Wu, Sixi Zhu. Horizontal waterbody effect of hexachlorocyclohexane [J]. Sustainable Energy and Environment Protection. 2015, 191-195.

13. Dongfang Yang, Fengyou Wang, Xiuqin Yang, Yunjie Wu and Sixi Zhu. Water's effect of benzene hexachloride [J]. Advances in Computer Science Research. 2015, 2352: 198-204. 